\title{
Busíris, um drama satírico de Eurípides
}

Busiris, a satyr play by Euripides

\author{
Wilson Alves Ribeiro Jr. ${ }^{1}$ \\ e-mail: epwidos@my.com \\ orcid: http://orcid.org/0000-0002-6841-5697
}

DOI: http://dx.doi.org/10.25187/codex.v6i1.15237

Resumo: Busíris é um dos dramas satíricos de Eurípides, incompleto e de data incerta. Este artigo contém um panorama dos mitos sobre Héracles e Busíris e sua iconografia; a tradução dos testemunhos e fragmentos conhecidos; e uma reconstrução conjetural do drama satírico, baseada nos escassos dados disponíveis.

Palavras-chave: Busíris; Héracles; Eurípides; drama grego; drama satírico; fragmentos

Abstract: Busiris is one of Euripides incomplete satyr plays and its date is uncertain. This paper contains an overview of myths on Busiris and Heracles, his iconography, a Portuguese translation of testimonia and known fragments, and a conjectural reconstruction of the satyr play, based on scanty available data.

Keywords: Busiris; Heracles; Euripides; Greek drama; satyr play; fragments

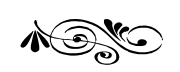

O drama Busíris consta do catálogo de obras de Eurípides (test. i) e sua natureza satírica foi estabelecida por uma hipótese parcialmente conservada (test. iiia) e pelo testemunho de Diomedes, o Gramático (test. ii). Há pouquíssimos fragmentos, totalizando apenas dois versos e algumas palavras isoladas. Não é possível datar a primeira apresentação do drama, nem mesmo de forma aproximada².

${ }^{1}$ Médico, Mestre (2006) e Doutor (2011) em Letras Clássicas pela Universidade de São Paulo, pesquisador do Grupo de Pesquisa "Estudos sobre o Teatro Antigo" (FFLCH-USP, CNPq, SBEC). Membro da Sociedade Brasileira de Estudos Clássicos.

${ }^{2}$ Há algumas conjeturas, porém insuficientemente fundamentadas (VAN LOOY, 2002, p. 41). 


\section{O mito de Héracles e Busíris ${ }^{3}$}

As aras de Busíris infamado, Onde os hóspedes tristes imolava, Terás certas aqui, se muito esperas. Luís de Camões, Lusíadas ii.62.5-7

"Busíris" é o nome do mítico faraó 4 que sacrificava estrangeiros que chegavam ao Egito, até Héracles interromper essas atividades de forma radical e definitiva. O mito remonta, no mínimo, à primeira metade do século VI a.C., quando pintores de vasos começaram a representar a história na cerâmica grega. As fontes literárias mais antigas datam de meados do século V a.C.

Das primeiras imagens do mito, restam apenas alguns fragmentos de cerâmica, como, por exemplo, os da taça de figuras negras decorada pelo Pintor de Heidelberg c. 565 a.C. (Palermo 1986), mas um vaso de figuras negras decorado pelo Pintor do Balanço c. 540-530 a.C. (Cincinnati 1959.1) tem a cena completa ${ }^{5}$. Vê-se um altar e, sobre ele, o corpo de um egípcio bem vestido, provavelmente o próprio Busíris; diante dele, Héracles, corpo coberto com a pele do Leão de Nemeia, segura um egípcio pelo pé e o utiliza como clava para atingir outros egípcios que o cercam. Dois deles têm facas nas mãos e a reação violenta do herói sugere que era ele, com certeza, a vítima sacrificialo.

\footnotetext{
${ }^{3}$ Fontes literárias mais importantes, anteriores a 400 a.C.: Ferécides (FGrH 3 F 17), Paniassis (F 11) e Heródoto (2.45). Posteriores a 400 a.C.: Isócrates (Bus. 11.10), Calímaco (F 44), Diodoro Sículo (4.18.1 e 4.27.2-4), Ovídio (Ars Am. 1.647-52), Apolodoro (2.5.11), Plutarco (Vit. Thes. 11), Agaton de Samos (FGrH 843 F 3), Díon Crisóstomo (8.32) e Higino (31.2; 56; 157.4). Fontes iconográficas: Palermo 1986, Cincinnati 1959.1, Viena 3576, Atenas 9683, Nova York 15.27, entre outras. Há vários sumários sobre a contribuição de cada fonte; ver Laurens (1986), Miller (2000), Papillon (2001), Livingstone (2001), Roumpi (2011) e referências.

${ }^{4}$ Ver Carrez-Maratray (2004).

${ }^{5}$ Ver cincinnatiartmuseum.org/art/explore-the-collection?id=13142897.

${ }^{6}$ Não há inscrições, mas é possível reconhecer os personagens pelos elementos iconográficos (e.g. o couro do leão que recobre Héracles, a cabeça raspada e as vestimentas não gregas dos egípcios) e pela comparação com as fontes literárias.
} 


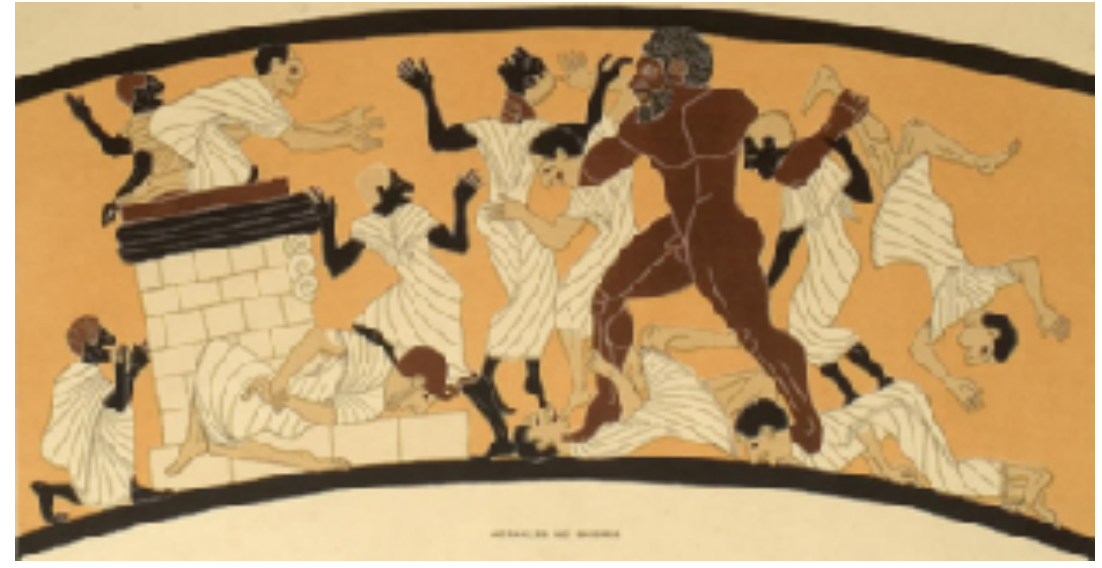

Fig. 1. Héracles dizima Busíris e seus servos. Cena de hídria ceretana de figuras negras de Cervetri, c. 530 a.C. Viena 3576. Desenho de Karl Reichhold (FURTWANGLER \& REICHHOLD, 1904, tafel 51). Fonte: Universitätsbibliothek Heidelberg, CC BY-SA.

A Fig. 1 é um desenho da cena pintada em vaso de figuras negras pouco mais recente (Viena 3576, c. 530 a.C.). O arranjo dos personagens é muito semelhante, com importantes variações na indumentária: Héracles, gigantesco e heroicamente nu, ataca com violência egípcios totalmente vestidos com elaboradas túnicas e mantos, em polvorosa e espalhados em torno do altar. Alguns estão mortos aos pés do herói e um deles, que ostenta o uraeus $^{7}$, com certeza representa o próprio Busíris. A mesma cena se repete, com variações, em pouco mais de trinta vasos de figuras negras ou de figuras vermelhas criados no final do Período Arcaico e no Período Clássico. Acredita-se que a imagem do vaso de Viena foi inspirada em pinturas murais egípcias (MILLER, 2000, pp. 417-20) e que algumas das representações do mito, como as dos dois vasos mencionados supra, têm caráter caricatural (LAURENS, 1986, p. 149) e até mesmo apelo cômico (PAPILLON, 2001, pp. 78-80; LIVINGSTONE, 2001, pp. 88-9).

7 Do egípcio j’r.t (= iaret), lat. uraeus e gr. oủpaĩos, "cobra erguida". Representação estilizada de serpente que simbolizava, na Antiguidade, a realeza egípcia e a autoridade de origem divina. Os faraós usualmente ostentavam o uraeus em coroas, capacetes e máscaras fúnebres. 
As fontes textuais mais antigas são ligeiramente anteriores ou contemporâneas de Eurípides e se ajustam perfeitamente às cenas de vasos (KANNICHT, 2004, p. 368). Ferécides menciona Héracles e Busíris, Paniassis dá alguns detalhes sobre o sacrifício humano no Egito e Heródoto descreve o episódio. Nem Paniassis, nem Heródoto mencionam Busíris explicitamente, mas as informações das três fontes se completam e revelam os principais elementos narrativos do mito. Héracles estava a caminho do Jardim das Hespérides, em busca das maçãs de ouro de $\mathrm{Hera}^{8}$ e, depois de encerrar a carreira do gigantesco Anteu, na Líbia, dirigiuse ao Rio Nilo e a Mênfis, onde Busíris, filho de Posídon, matava estrangeiros no altar de Zeus. O herói se deixou coroar e, aparentando tranquilidade, foi levado em procissão até o altar ${ }^{10}$. Quando os sacerdotes se preparavam para sacrificá-lo, reagiu e matou Busíris, seu filho Ifidamas,

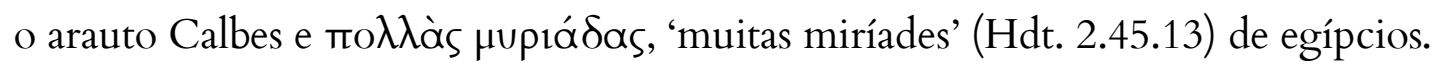

Fontes posteriores a Eurípides dão colorido adicional à história. De Calímaco (F 44)

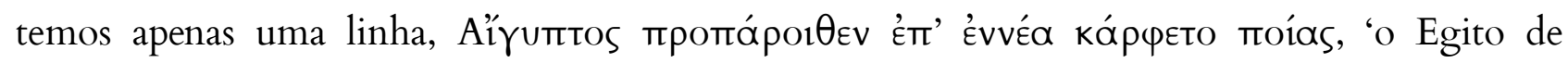
antigamente sofreu uma seca de nove anos', mas Ovídio e Apolodoro provavelmente se inspiraram em seu poema (HOLLIS, 1977, p. 154; HARDER 2012, p. 373-4) e, nesse sentido, pode-se dizer que os três conservaram versões semelhantes do mito. Após nove anos de seca,

\footnotetext{
${ }^{8} \mathrm{O} 11^{\circ}$ Trabalho de Héracles, na lista canônica de Apolodoro (2.5.11).

9 Posídon era pai de vários vilões da mitologia grega, e.g. o ciclope Polifemo, os gigantescos Oto e Efialtes (os alóadas), Cércion, Círon, Procusto, Anteu e Busíris.

10 O sacrifício grego com vítima seguia ritual mais ou menos estabelecido (BURKERT 1977, pp. 127-30) pela tradição. Os participantes colocavam coroas de ramos e a vítima (boi, carneiro etc.) era enfeitada e levada, em procissão, ao altar; esperava-se que ela seguisse docilmente, em anuência. A faca sacrifical seguia à frente, em um cesto, coberta com grãos de cevada e bolos. Depois da lavação das mãos e da prece, a água lustral e os grãos eram lançados sobre o altar e sobre a vítima, de quem se cortava pequena mecha de pelos, lançada ao fogo antes da morte da vítima. O altar devia ficar manchado de sangue. Ossos, porções não comestíveis e outras oferendas (a parte dos deuses) eram queimadas no altar; a carne e algumas vísceras (a parte dos homens), eram assadas e distribuídas aos participantes.
} 
Busíris foi informado pelo adivinho Frásio ${ }^{11}$, de Chipre, que o problema seria resolvido se, anualmente, um estrangeiro fosse sacrificado a Zeus. O rei começou pelo próprio adivinho e, daí em diante, fez o mesmo com todos os estrangeiros que chegavam ao Egito. Diodoro Sículo introduziu novos elementos ao mito tradicional, contando que as Hespérides eram as belíssimas filhas de Atlas, rei vizinho do Egito ${ }^{12}$, e que Busíris contratou piratas para raptá-las. Héracles, porém, matou os piratas e Busíris, resgatou as jovens e as devolveu a Atlas, que, agradecido, ajudou o herói a completar sua tarefa e, de quebra, ensinou-lhe astronomia.

Algumas fontes apresentam apenas variações do nome e da genealogia dos personagens. A mãe de Busíris, por exemplo, era Lisianassa, segundo Apolodoro; Anipê, segundo Agaton de Samos; e Líbia, segundo Isócrates. Outros autores fornecem detalhes suplementares, e.g. Agaton e Higino (31.2) contam que Héracles matou Busíris com sua clava.

Polícrates, Isócrates, Eurípides e os poetas cômicos Epicarmo, Cratino, Antífanes, Efipo e Mnesímaco utilizaram o mito de Héracles e Busíris em suas obras. Os discursos de Polícrates e de Isócrates são exercícios de retórica que discutem a credibilidade das histórias contadas sobre Busíris, seus feitos e desfeitos. O discurso de Polícrates não sobreviveu, mas temos o de Isócrates na íntegra. De Eurípides e dos poetas cômicos, restam apenas fragmentos de seus dramas, todos eles intitulados Busíris.

O orador Díon Crisóstomo, que não menciona a história do sacrifício, descreve Busíris

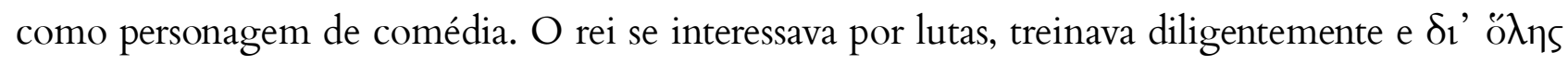

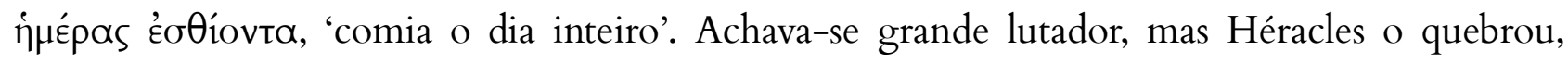

\footnotetext{
${ }^{11}$ Segundo Apolodoro; em Ovídio, o nome do adivinho é Trásio.

12 No mito grego original, que remonta no mínimo aos séculos VIII-VII a.C., Atlas é filho do titã Jápeto, foi punido por Zeus após a titanomaquia e condenado a sustentar o céu com os ombros (e.g. Od. 1.52-4, Hes. Theog. 517-20). As Hespérides eram originalmente filhas de Nix, a Noite, e guardavam maçãs de ouro no jardim de Hera, situado nos confins do mundo conhecido (Hes. Theog. 215-6; Eur. Hipp. B 742-51).
} 


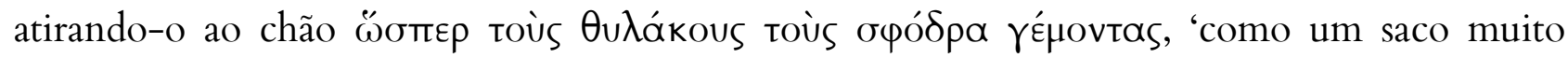
cheio'. É possível que essa descrição tenha sido inspirada pelo drama de Eurípides (VAN LOOY, 2002, p. 39) ou por um dos poetas cômicos; não se pode afastar, por outro lado, a possibilidade de Díon ter confundido Busíris com o gigantesco Anteu, que desafiava e matava os passantes e foi derrotado e morto por Héracles na Líbia (Pind. Isthm. 4.52-7; Pherec. FGrH 3 F 76)13, antes de o herói se dirigir ao Egito.

\section{Fontes, tradução e comentários ${ }^{14}$}

Um fragmento de papiro (P. Oxy. 3651) contém parte da antiga hipótese do Busíris (24-6) e o início do primeiro verso (25). Os outros fragmentos, de atribuição confirmada ou ainda em debate, vêm de fontes secundárias: Estobeu, Hesíquio, Clemente de Alexandria, Apolodoro, Fócio e as Anedotas Gregas de Oxford. Dos vasos conhecidos, apenas uma taça ática de figuras vermelhas (Berlim 2534) pode ter alguma relação com o drama satírico.

\subsection{Testemunhos}

\section{i. Catálogo de dramas $\mathbf{I}^{15}$. Busíris.}

ii. Diom. 3.10.9. A farsa atelana latina ${ }^{16}$ difere do drama satírico grego, pois nos dramas satíricos as máscaras são geralmente exibidas pelos sátiros, ou são engraçadas, semelhantes a sátiros, Autólico, Busíris; na atelana (são exibidas) máscaras oscas, como Maccus. ${ }^{17}$

\footnotetext{
${ }^{13}$ Numerosas obras de arte representam a luta entre Héracles e Anteu a partir do século VI a.C., antes das fontes escritas. A representação mais antiga, com o nome dos lutadores identificando as figuras, é uma ânfora de figuras negras do Grupo de Leagros datada de 550-500 a.C. (Munique 1417).

14 Ver também Ribeiro Jr. (2015, p. 174).

${ }^{15}$ IG XIV 1152 col. I 16.

${ }^{16} \mathrm{~A}$ atelana era peça cômica de curta duração e caráter farsesco, muitas vezes marcada pelo improviso. Original de Atella, cidade da Campânia de língua osca e localizada no sul da península Itálica, foi introduzida em Roma no século IV a.C. Os atores usavam máscaras grotescas e representavam personagens-tipo, como Maccus (estúpido e astucioso), Pappus (velho esperto), Buccus (simplório e divertido), Dossenus ou Manducus (corcunda e filósofo), que usualmente ridicularizavam acontecimentos contemporâneos, autoridades e outras pessoas de destaque.

${ }_{17}$ O gramático Diomedes aparentemente presenciou o drama satírico, uma vez que foi capaz de descrever as máscaras dos atores que representaram os sátiros e Busíris, em comparação com a atelana.
} 


\subsection{Hipótese e personagens do drama}

iiia. P. Oxy. 3651.22-7, século. II-III

drama satírico Busíris, cujo início é:

] ó divindade [

e eis a hipótese:

] maçãs [

sátiros $^{18} \ldots[$

Personagens do drama. Busíris, Héracles, Coro de sátiros ${ }^{19}$.

\subsection{Iconografia}

Berlim 2534. Taça de figuras vermelhas do Pintor do Louvre G 456, 450-440 a.C. Há duas cenas na parte externa e uma na parte interna, no fundo. As duas cenas externas representam a condução de Héracles até Busíris. Os egípcios são jovens, têm alguns traços negroides e usam roupas gregas; o herói, entre dois egípcios, está com um dos pés preso a uma corda, usa a tradicional pele de leão e carrega sua clava; Busíris está sentado, com um cetro na mão direita,

\footnotetext{
18 A estrutura das frases, razoavelmente legível após a reconstrução de Cockle (1984), mostra que se trata de hipótese do tipo narrativo, infelizmente incompleta. A presença da palavra $\mu \tilde{\eta} \lambda \alpha$, 'maçã' (25), associada ao título

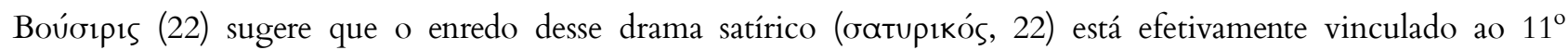
Trabalho de Héracles e ao episódio do encontro entre Héracles e Busíris.

19 Além do Coro de sátiros (test. ii: satyris; test. iiia.26: oátupol), só podemos ter certeza da presença de Busíris

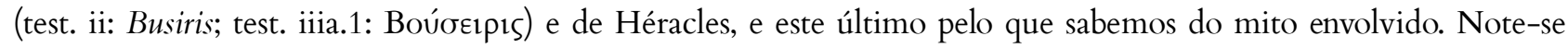
que Ciclope de Eurípides tem estrutura praticamente tão enxuta quanto essa: um vilão (Polifemo), um herói (Odisseu) e o Coro de sátiros, com Sileno à frente.
} 
ricamente trajado. $\mathrm{Na}$ cena do interior ${ }^{20}$ se vê Héracles sentado em uma rocha, sobre a pele do leão, bebendo com a mão direita e segurando a clava com a mão esquerda. Diante dele, de pé, um sátiro observa, enócoa na mão direita.

\subsection{Fragmentos}

Prólogo. Dispomos de parte do primeiro verso do Busíris (F 312b), que obviamente pertence ao prólogo. Ao prólogo pertence também, possivelmente, o incerto $\mathrm{F}^{\star \star} 955 \mathrm{~h}$.

${ }^{\star \star}$ 955h Ámon, o senhor com face de carneiro

que habita estas terras sem água, fez esta profecia: ${ }^{22}$

Párodo, episódios, estásimos e êxodo. Não há elementos para situar os demais fragmentos nas partes do drama que habitualmente seguem o prólogo.

\footnotetext{
${ }^{20}$ Imagem disponível em greciantiga.org/img.asp?num=1242.

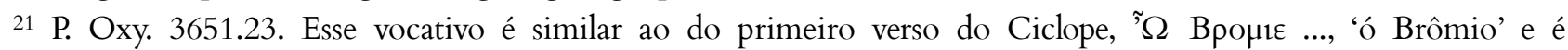
provavelmente declamado por Sileno ou por um dos sátiros.

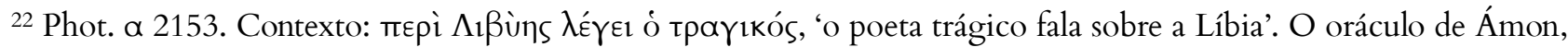
nome egípcio de Zeus (Hdt. 2.42), localizava-se em área desértica da Líbia (Hdt. 1.43 e 2.55; Paus. 3.18.3). Embora geograficamente distintas, para os gregos do Período Clássico a Líbia, associada a Cirene, e o Egito, associado a Náucratis, representavam um tanto indistintamente a longínqua e mítica África (COLLARD \& CROPP, v. 2, p.

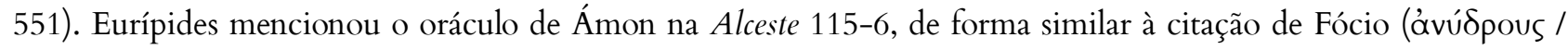

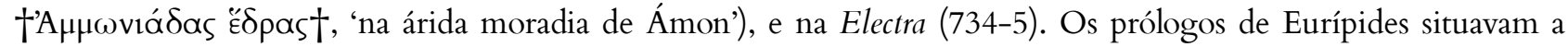
audiência no mito a ser abordado no drama e também no local onde a ação se passava e.g. Ciclope 18-22, Andrômaca 16-20, Ifigênia em Táuris 29-34 (ver Ar. Ran. 946-7; HAMILTON, 1972; GEACH, 2016; e referências). Menção a uma profecia e o uso do demonstrativo ( $(\alpha ́ \delta \varepsilon)$, usuais nos prólogos euripidianos, sugerem que o fragmento pode ser parte do prólogo do Busíris. Kannicht (TrGF 5.2 ad loc.) comenta que o fragmento poderia também pertencer ao êxodo, o que me parece muito menos provável. Outras atribuições possíveis: Andrômeda e Faetonte, tragédias associadas à Etiópia.
} 
313 para um escravo, não é possível dizer a verdade, se acaso ela não é conveniente aos seus mestres. ${ }^{23}$

$313 a \quad \ldots{ }^{24}$

$314 \quad$ purificar (ritualmente) ${ }^{25}$

315 tendo certeza26

\subsection{Fragmentos incertos}

${ }^{\star} 879$ esse, o melhor e mais hospitaleiro ${ }^{27}$

*907 comia figos verdes com carne de vaca, uivando tão desafinado que até o bárbaro notava. ${ }^{28}$

adesp. 33 e fogo brilhava

em seus olhos. ${ }^{29}$

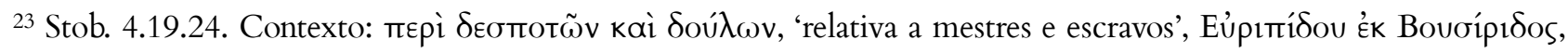
'do Busíris de Eurípides'. É possível que se trate de fala dos próprios sátiros, uma vez que eles frequentemente falam de si mesmos como escravos de alguém, e.g. de Polifemo (Eur. Cyc. 31; 76-81) e de Euristeu (Eur. F 375).

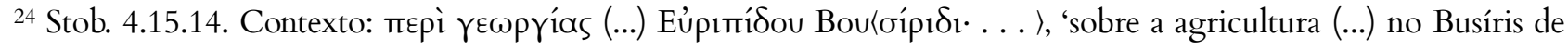
Eurípides' (LUPPE 1988, p. 504). A passagem está danificada no manuscrito de Estobeu.

${ }^{25}$ Hsch. a 648. Contexto: Bovoípı $\delta$, 'no Busíris'. Referência ao sacrifício dos estrangeiros que chegam ao Egito, em geral, ou ao malogrado sacrifício de Héracles, em particular.

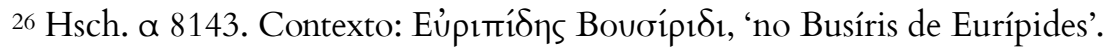

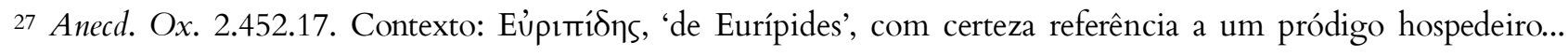
Segundo Wilamowitz (1906, p. 192), o fragmento é passagem de um drama satírico e se trata provavelmente de irônica referência a "pródigos" hospedeiros como Busíris e Círon.

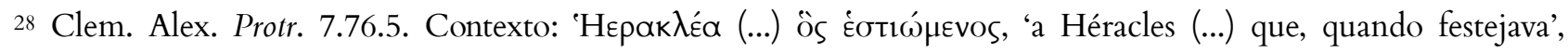
referência aos "exageros gastronômicos" de Héracles (e.g. Eur. Alc. 756-64). O fragmento foi atribuído por Wilamowitz (1906, p. 192) ao Busíris, mas a maioria dos eruditos considera o fragmento mais condizente com o Sileu (cf. Eur. Sileu test. iiia, KANNICHT 2004, v. 5.2, p. 672).

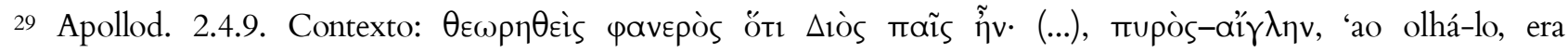
evidentemente um filho de Zeus' (...) etc. A passagem foi atribuída por Nauck (1889, p. 845 ad loc.) a um poeta trágico e, talvez, ao Sileu; Wilamowitz anotou à mão, em seu exemplar: "Eur. Busiris?". 


\section{Reconstruindo o Busíris}

Os egípcios mantinham relações amigáveis com os gregos (Hdt. 2.178-9; Diod. Sic. 1.67.9-11) desde o século VII a.C., pelo menos. Náucratis, no delta do Nilo, era movimentado entreposto comercial onde se encontravam egípcios, gregos, fenícios e outros povos (BRAUN, 1982; TOVAR, 2010). O mito de Héracles e Busíris reflete, por outro lado, crenças arraigadas no imaginário grego sobre o caráter não hospitaleiro dos bárbaros e, notadamente, dos egípcios, a despeito da admiração de Heródoto, Platão e outros gregos cultos (LAURENS, 1986, pp. 150-51) $)^{30}$ por essa antiga cultura.

Eurípides explorou o tema da xenofobia egípcia (Str. 17.1.19; NIMIS, 2004) em duas obras ambientadas no Egito, o drama satírico Busíris e a tragédia Helena (412 a.C.)31. Em algumas passagens da Helena, Eurípides faz alusões diretas às atitudes pouco hospitaleiras dos egípcios em relação aos helenos. Helena diz a Teucro que Teoclímeno, o rei do Egito, kteíveı

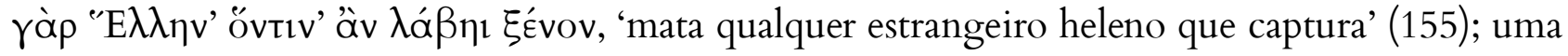

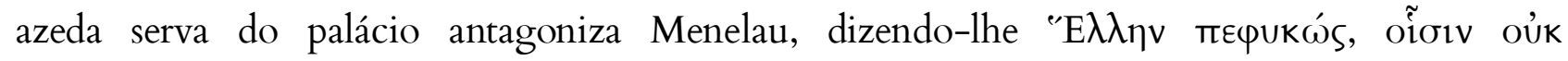
Ł̇iıтрофaí, 'és grego, e para esses não há consideração' (440)32; e Teoclímeno confirma,

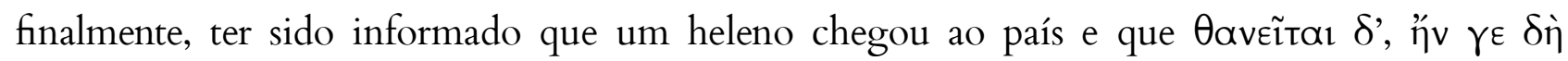
$\lambda \eta \varphi \theta \tilde{\eta} 1$ uóvov, 'será morto, basta ser apanhado' (1176). Teoclímeno desejava Helena e não

\footnotetext{
${ }^{30}$ Sobre a falta de hospitalidade dos bárbaros em geral, ver Miller (2000) e Pearce (2007); sobre os egípcios, ver o livro 2 de Heródoto; os diálogos Timeu e Crítias, de Platão; Froidefond (1971), Laurens (1986, pp.149-151), Vasunia (2001, pp. 185-93) e Carrez-Maratray (2004). O Busíris de Isócrates também dá muitas informações sobre a visão dos gregos do século IV a.C. sobre o Egito (ver Livingstone, 2001).

${ }^{31}$ Para a influência do Egito na tragédia grega, ver Froidefond (1971, pp. 69-112 e 209-223); na comédia grega, Berti (2002).

32 Cf. interpretação de Allan (2008, ad loc.).
} 
queria ver nenhum heleno por perto, mas os vv. 155, 440 e 1176 sugerem que sua xenofobia tinha caráter muito mais amplo. No Busíris de Eurípides, o antagonismo provavelmente transparecia na oposição formular entre gregos, representados por Héracles, e egípcios, representados por Busíris.

É impossível reconstruir o Busíris euripidiano com os parcos elementos à nossa disposição. Hartung (1844, p. 360-62) fez uma tentativa, mas considerou Busíris e Lâmia um único drama e baseou sua reconstrução na presença de Lâmia ${ }^{33}$ e no resgate das Hespérides, episódio introduzido por Diodoro Sículo ${ }^{34}$. Não me parece plausível que Eurípides tenha colocado dois vilões desse porte em um único drama satírico, e o próprio Hartung lembrou, no final do texto (p. 362), que "não conhecemos a sequência de eventos da composição dramática". É verdade, mas os elementos básicos do mito e os conhecimentos disponíveis sobre os recursos dramáticos utilizados por Eurípides no Ciclope e em outros dramas permitem, ao menos, algumas conjeturas quanto ao arranjo das cenas do Busíris e, talvez, quanto a alguns detalhes do drama.

Busíris não era fisicamente um monstro mas, para os gregos, o rei bárbaro que sacrificava compulsivamente os estrangeiros que apareciam em seu país era, sem dúvida, uma espécie de ogro (O’SULLIVAN \& COLLARD, 2013, p. 30). A presença de Héracles, herói especializado em livrar o mundo de monstros de todos os tipos (Eur. F 692), aponta diretamente para um dos temas satíricos caros a Eurípides, o do herói errante que castiga o monstro e, com isso, salva os pobres sátiros e, às vezes, a si mesmo. É provável, consequentemente, que os

\footnotetext{
33 O F 312a, que menciona explicitamente Lâmia, era antigamente associado ao Busíris, mas é hoje considerado parte do drama satírico Lâmia e foi renomeado para F 472m (ver nota 40, infra).

${ }^{34}$ Diodoro provavelmente só racionalizou o mito do $11^{\circ}$ Trabalho de Héracles (que ele considerava o último), sem acrescentar elementos não preservados pelas fontes antigas.
} 
personagens do Busíris - Héracles, Busíris e os sátiros - atuassem de acordo com esse tema, bem conhecido graças ao Ciclope e a outros dramas satíricos ${ }^{35}$, e que a ação dramática seguisse os principais elementos do mito conhecido.

Em linhas gerais, o Busíris de Eurípides deve ter começado com uma evocação às divindades (F 312b) e, logo depois, Sileno ou um dos sátiros conta como chegaram ao Egito (F ${ }^{\star \star} 955 \mathrm{~h}$ ) e foram escravizados por Busíris (F 313). Héracles aparece e é reconhecido pelos sátiros (F adesp. 33), a quem menciona a busca pelo Jardim das Hespérides (P. Oxy. 3651.22) e, por sua vez, é informado do risco de estrangeiros passarem pelo Egito. Mesmo assim, Héracles procura Busíris para pedir hospitalidade $\left(\mathrm{F}^{\star} 879\right)$ ou os egípcios o detêm e o conduzem até seu rei. Após algum tipo de debate entre Héracles e Busíris ( $\left.F^{\star} 907\right)$, o herói é encaminhado ao sacrifício ( $F$ 314), mas, fora de cena, mata Busíris e entourage. De volta ao palco, avisa os sátiros que agora estão livres.

É bem possível que Eurípides tenha apresentado o encontro entre Busíris e Héracles de forma semelhante à dos poetas cômicos, a julgar pela lembrança de Dion Crisóstomo do Busíris glutão e fanfarrão (Or. 8.32). No F 21 do Busíris de Epicarmo, um mensageiro descreve - a Busíris, provavelmente - a aterrorizante voracidade do herói durante uma refeição, e profetiza:

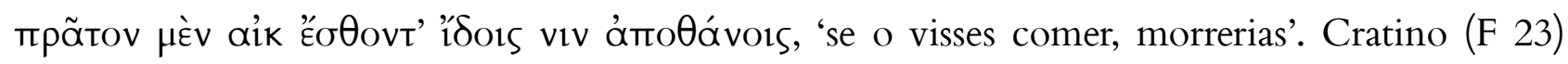

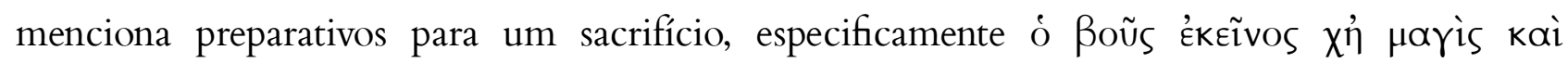

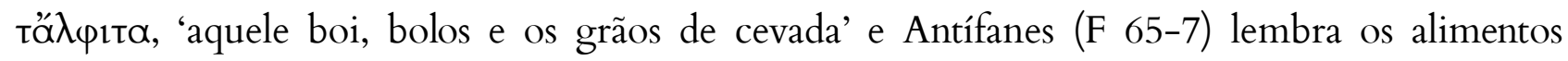
levados para o sacrifício. Na comédia de Efipo (F 2), Héracles conta que vai aos combates embriagado de vinho, como todo argivo; em Mnesímaco (F 2) ele diz que é beócio, fala pouco e

\footnotetext{
35 Eurípides recorreu ao tema do herói contra o ogro na maioria de seus dramas satíricos conhecidos: Busíris, Ceifeiros (?), Ciclope, Círon, Euristeu e Sileu. Ver Ribeiro Jr. (2015, pp. 174-9).
} 


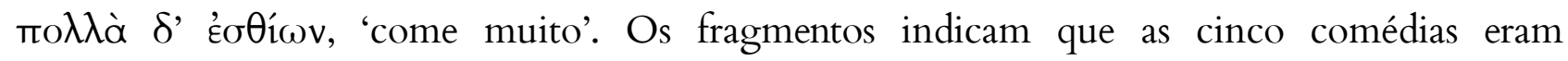
provavelmente lembradas pelos excessos de comida e bebida dos personagens, como no drama satírico Ônfale, de Íon de Quios (F 20; 26-30), e em diversos dramas da Comédia Intermediária (LLOPIS, GÓMEZ \& ASENSIO, 2007, pp. 44-6).

A gulodice está documentada na cerâmica grega já no século VI a.C. (MITCHELL, 2009, pp. 125-8; 152-60), mas somente no século seguinte o tema parece ter chegado à comédia (OLSON, 2007, pp. 33-40; WILKINS, 2000). Epicarmo foi, aparentemente, o primeiro poeta a recorrer ao proverbial apetite de Héracles por comida e bebida36 e, de meados do século V a.C. em diante, a gula de Héracles, atletas37, vilões e sátiros (e.g. Eur. Cyc. 139-61) se tornou lugarcomum tanto da comédia quanto do drama satírico ${ }^{38}$. Na Comédia Antiga, o Héracles glutão se tornou tão habitual que em 422 a.C. Aristófanes fez o personagem Xântias prometer, em Vespas (60), não apresentar Héracles completamente enganado quanto ao seu jantar.

Talvez Héracles tenha desafiado Busíris para uma competição de comilança, recurso utilizado por Eurípides no drama satírico Sileu (F 691), o que tem muitas possibilidades cômicas e é compatível com o desfecho relembrado por Díon Crisóstomo. Eurípides também recorreu ao tema da gulodice de Héracles na tragédia Alceste (747-832), representada em 438 a.C., bem depois de Epicarmo, mais ou menos na mesma época de Cratino e meio século antes de Antífanes, Efipo e Mnesímaco.

E, finalmente, Héracles pode ter recorrido à sua clava, representada no vaso do Pintor do Louvre G 456 e mencionada por Agaton e Higino (31.2), para matar Busíris. No drama satírico

\footnotetext{
36 Epicarmo mencionou os excessos alimentares e etílicos de Héracles no Busíris (F 21) e também nas comédias Casamento de Hebe (F 42-75) e Héracles da Casa de Folo (F 78-9).

37 Ver drama satírico Autólico A (Eur. F 282).

${ }^{38}$ Ver lista de dramas satíricos em O’Sullivan \& Cropp (2013, p. 509, s.v. "Food, feasting, gluttony").
} 
Sileu, o herói provavelmente despachou o vilão com sua clava (F 693), e, no Busíris, Eurípides pode ter utilizado o mesmo recurso. Agaton e Higino viveram séculos depois de Eurípides e não é impossível que sua informação tenha vindo diretamente do drama satírico.

\section{Textos originais}

A fonte padrão dos testemunhos e fragmentos é Kannicht $(2004$, v. 1 = TrGF 5.1.19= Eur. F 312b-313), utilizada aqui; foram também consultadas as edições de Van Looy (2002) e Collard \& Cropp (2008, v. 1, pp. 318-21).

\subsection{Testimonia}

\section{i. Catalogus fabularum I Boúoeıpıs $\varsigma^{39}$.}

ii. Diom. 3.10.9. Latina atellana a Graeca satyrica differt, quod in satyrica fere Satyrorum personae inducuntur, aut si quae sunt ridiculae similes Satyris, Autolycus Busiris; in atellana Oscae personae, ut Maccus.

iiia. P. Oxy. 3651.22-7 (saec. II-III)

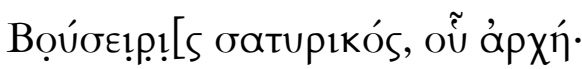

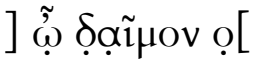

ๆ̣ $\delta$ บ்

]. . $\alpha \mu \tilde{\eta} \lambda \alpha \delta .[$

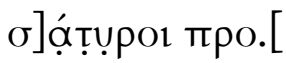

\footnotetext{
${ }^{39} \mathrm{O}$ título do drama satírico é usualmente grafado Boúoıpıs, mas há várias ocorrências da forma Boúoєıpıs, e.g. na hipótese (test. iiia.1) e no título da comédia homônima de Epicarmo (F 81.10).
} 


\subsection{Fragmenta certis fabula adscrita}

$312 \mathrm{a}=472 \mathrm{~m}^{40}$

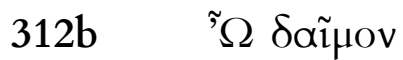

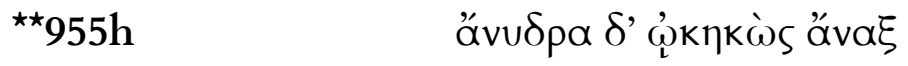

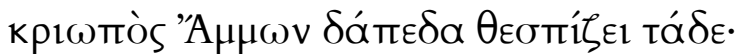

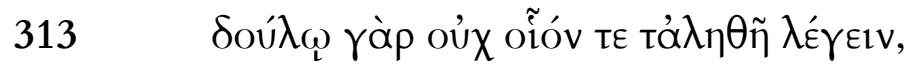

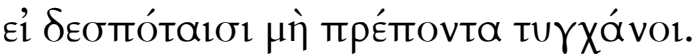

$313 a$

$314 \quad$ árvíoal

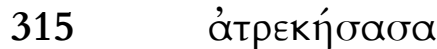

\subsection{Incertarum fabularum fragmenta}

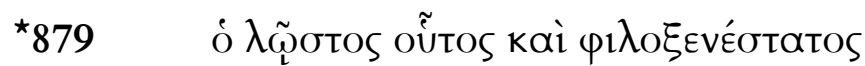

40 Ver Lâmia (TrGF v. 5.1, p. 517-8). 
adesp. 33

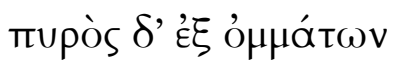

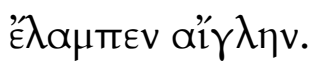

\section{Referências:}

\section{Museus e coleções de arte:}

Atenas Museu Arqueológico Nacional. Atenas, Grécia.

Berlim Coleção de Antiguidades (Museu Antigo e Museu de Pérgamo). Berlim, Alemanha.

Cincinnati $\mathrm{Museu}$ de Arte. Cincinnati, Estados Unidos.

Munique Coleções Estatais de Antiguidades. Munique, Alemanha.

Nova York Museu Metropolitano de Arte. Nova York, Estados Unidos.

Palermo Museu Arqueológico Regional. Palermo, Itália.

Viena Museu de História da Arte. Viena, Áustria.

\section{Autores e obras}

ALLAN, W. Euripides Helen. Cambridge: Cambridge University Press, 2008.

BERTI, M. “L’Egitto nella commedia greca”. Aegyptus, v. 82, 2002, pp. 93-112.

BRAUN, T. “The greeks in Egypt”. In: BOARDMAN, J. \& HAMMOND, N. (Ed.). The Cambridge Ancient History. Cambridge: Cambridge University Press, 1982, pp. 32-56.

BURKERT, W. Religião grega na época clássica e arcaica. Trad. M. J. Simões Loureiro. Lisboa: Calouste Gulbenkian, 1993 [1977]. 
CARREZ-MARATRAY, J-Y. "Bousiris, le pharaon inexistant, et le stéréotype grec du roi juste”. In: GRANDIÈRE, M. \& MOLIN, M. (Ed.) Le stéréotype, outil de régulations sociales. Rennes: Presses Universitaires de Rennes, 2004, pp. 201-212.

COCKLE, H. M. (Ed.). The Oxyrhynchus Papyri, v. LII (Graeco-Roman Memoirs, 72). London: Egypt Exploration Society, 1984, pp. 17-22.

COLLARD, C. \& CROPP, M. Euripides fragments, 2 v. Cambridge MA / London: Harvard University Press, 2008.

FROIDEFOND, C. Le mirage égyptien dans la littérature grecque d'Homère à Aristote. Aix-enProvence: Ophrys, 1971.

FURTWAENGLER, A. \& REICHHOLD, K. Griechische vasenmalerei: auswahl hervorragender vasenbilder (Serie I, Tafeln). München: Bruckmann, 1904.

GEACH, J. The Euripidean Prologue. Dissertação (Master in Art). Department of Classics, The University of Arizona, Tucson, 2016.

HAMILTON, R. "Prologue Prophecy and Plot in Four Plays of Euripides". American Journal of Philology, v. 99, n. 3, 1978, pp. 277-302.

HARDER, A. Callimachus Aetia: introduction, text, translation and commentary, v. 1. Oxford: Oxford University Press, 2012.

HARTUNG, J. A. Euripides restitutus, v. alterum. Hamburg: Freiderich Perthes, 1844.

HOLliS, A. S. Ovid Ars Amatoria, Book I. Oxford: Oxford University Press, 1977.

KANNICHT, R. Tragicorum Graecorum Fragmenta, v. 5.1 (pars prior) / v. 5.2 (pars posterior). Göttingen: Vandenhoeck \& Ruprecht, 2004.

LAURENS, A-F. “Bousiris”. In: Lexicon Iconographicum Mythologiae Classicae, v. III. Zurich / München: Artemis, 1986, pp. 147-152.

LIVINGSTONE, N. A commentary on Isocrates'Busiris (Supplementum Mnemosyne, v. 223). Leiden: Brill, 2001.

LUPPE, W. “Zu einer Stobaios-Stelle aus Euripides”. Hermes, v. 116, n. 4, 1988, pp. 504-5.

LLOPIS, J. S.; GÓMEZ, R. M. \& ASENSIO, J. P. Fragmentos de la Comedia Media. Madrid: Gredos, 2007.

MILLER, M. C. "The myth of Bousiris: ethnicity and art". In: COHEN, B. (Ed.). Not the classical ideal: Athens and the construction of the other in greek art. Leiden: Brill, 2000, pp. 413-42.

MITCHELL, A. G. Greek vase-painting and the origins of visual humour. Cambridge / New York: Cambridge University Press, 2009.

NAUCK, A. Tragicorum graecorum fragmenta, editio secunda. Lipsiae: Teubneri, 1889. 
NIMIS, S. "Egypt in graeco-roman history and fiction". Alif: Journal of Comparative Poetics, Cairo, v. 24, 2004, pp. 34-67.

OLSON, S. D. Broken laughter: select fragments of greek comedy. Oxford: Oxford University Press, 2007.

O'SUlLIVAN, P. \& COLLARD, C. Euripides Cyclops and major fragments of greek satyr drama. Oxford: Oxbow, 2013.

PAPILLON, T. L. "Rhetoric, art and myth: Isocrates and Busiris". In: WOOTEN, C. W. \& KENNEDY, G. A. (Ed.) The orator in action and theory in Greece and Rome (Supplementum Mnemosyne, v. 225). Leiden: Brill, 2001, pp. 73-96.

PEARCE, S. J. K. The land of the body: studies in Philo's representation of Egypt. Tübingen: Mohr, 2007.

RIBEIRO JR., W. A. "Notas sobre os dramas satíricos fragmentários de Eurípides". In: SANTOS, F. B. \& OLIVEIRA, J. K. (org.) Estudos Clássicos e seus desdobramentos: artigos em homenagem à Professora Maria Celeste Consolin Dezotti. São Paulo: Cultura Acadêmica, 2015, pp. 165-182.

ROUMPI, A. "The killing of Bousiris: the vase-painter's idea of the musicians in the service of an egyptian king”. Imago Musae, v. 24, 2011, pp. 23-42.

TOVAR, S. T. "Greek in Egypt”. In: BAKKER, Egbert J. (Ed.) A Companion to the Ancient Greek Language. Oxford: Wiley \& Sons, 2010, p. 253-66.

VAN LOOY, H. "BOY $\Sigma I P Y \Sigma \Sigma$ ATIPIKO $\Sigma$ - Busiris, drame satyrique”. In: JOUAN, F. \& . Euripide, tragédies tome VIII 2e partie: Fragments de Bellérophon à Protesilas. Paris: Les Belles Lettres, 2002, pp. 37-47.

VASUNIA, P. The gift of the Nile: hellenizing Egypt from Aeschylus to Alexander. Berkeley / Los Angeles: University of California Press, 2001.

WILAMOWITZ-MOELLENDORFF, U. von. Kleine schriften, v. 1. Berlin: Weidmann, 1937 [1906].

WILKINS, J. The boastful chef: the discourse of food in ancient greek comedy. Oxford: Oxford University Press, 2000.

\section{1) (3)}

